\title{
Comportamento contrátil de barreiras selantes de solo estabilizado para base de lagoas de tratamento
}

\author{
Otoniel P. da Costa $^{1} \&$ José A. de Lollo ${ }^{1}$
}

\begin{abstract}
RESUMO
Barreiras selantes são dispositivos de proteção do subsolo em áreas de disposição de resíduos. No ambiente rural podem ser de grande utilidade para impermeabilização de fundo de lagoas de tratamento de resíduos porém sua construção deve ser simples e de baixo custo. Uma solução interessante é se usar, nesses casos, o solo local com pequena adição de cal ou cimento, de forma a atingir as propriedades de interesse. Um cuidado especial diz respeito ao comportamento contráctil desses materiais, que poderá comprometer seu uso. O presente trabalho apresenta resultados de ensaios de retração em laboratório em corpos-de-prova de solo arenoso, estabilizado com cal e cimento. As alterações na estrutura das misturas com o tempo foram verificadas com uso de microscopia eletrônica de varredura. O valor máximo de retração encontrado foi de 0,648\% para corpos-de-prova com até quatorze dias de cura. Após vinte e oito dias de cura, os valores foram inferiores a $0,5 \%$ indicando materiais de baixa retração. As imagens microscópicas indicam que parcela significativa da retração ocorre até os sete dias de cura. Os resultados mostram que os materiais apresentam comportamento contráctil apropriado ao uso, como barreiras de proteção.
\end{abstract}

Palavras-chave: barreiras de solo, solo arenoso fino, retração de solos

\section{Contraction properties of liners produced with stabilized soil for stabelization pond base}

\begin{abstract}
Liners were proposed as subsoil contamination protection devices for waste disposal sites. In the rural environment, they can be used to construct pond bottoms for liquid waste treatment, but the construction needs to be quick and cheap. A good technical solution for these situations is the use of local soil compacted with low quantities of cement or lime, obtaining good properties for this purpose. These barriers need special care about their contraction behavior which may compromise its use. This work shows the results of contraction tests in sandy soil specimens and others stabilized with lime and with cement. Soil structure changes during cure time were checked using electronic scan microscopy. Results show maximum soil contraction of $0.648 \%$ for specimen with 14 days cure process. After twenty eight days of cure the contraction values were lower than $0.5 \%$, which classifies the material as of low contraction. Electronic scan image shows significant material structure alteration up to seven days cure. Results show that studied mixtures had appropriate contraction behavior for liner usage.
\end{abstract}

Key words: stabilized soil liner, fine sandy soil, soil contraction 


\section{INTRODUÇÃO}

A disposição inadequada de resíduos na natureza e os riscos relacionados a este fato, têm sido alvo de inúmeros estudos, em todo o mundo. Essas pesquisas resultaram em tecnologias e mecanismos legais de controle, com o objetivo de reduzir riscos de contaminação.

Em função de seus custos e dificuldades técnicas de execução, essas tecnologias nem sempre são aplicáveis a todas as situações nas quais há necessidade de proteção do meio, o que acaba ocasionando a disposição ou tratamento inadequado dos resíduos.

Nas atividades do agronegócio é cada dia mais comum que as exigências dos órgãos ambientais ou a ausência de proteção dos recursos naturais gerem situações nas quais se necessita construir dispositivos de tratamento de resíduos líquidos. Quando se tem este tipo de situação, a solução técnica mais usual consiste em lagoas de tratamento de resíduos as quais, no entanto, para que não representem risco de contaminação do subsolo, devem ser construídas com camadas de fundo que reduzam a percolação de substâncias potencialmente poluidoras ou contaminantes.

Tais barreiras têm a função de reter uma parcela dos compostos e retardar ao máximo o transporte do restante, de forma que estes não atinjam as águas naturais ou o façam em concentrações baixas, de forma a serem considerados inócuos (Costa, 2005). Quando as barreiras são produzidas com materiais naturais, esses objetivos são atingidos com maior eficiência através do uso de argilas ou solos de textura fina e que, em sua composição, apresentem argilominerais com boa capacidade de troca catiônica (Rizzo, 2004) materiais nem sempre disponíveis nas proximidades da área de disposição, tornando seu uso pouco viável devido a custos com transporte.

No caso dos materiais artificiais, o mais comum na atualidade é o uso de dispositivos geossintéticos, como mantas; no entanto, mesmo com as recentes reduções de seus custos, o uso ainda é limitado por custo ou mesmo pelas dificuldades técnicas de execução, de forma a garantir sua integridade e eficácia; uma alternativa encontrada para sanar esta deficiência foi o desenvolvimento de barreiras de solos combinados com outros materiais. Dentre as possibilidades existentes, as misturas solo-cal e solo-cimento compõem a alternativa mais viável; sobretudo com baixo custo.

Trabalhos anteriores mostraram que misturas de solo laterítico arenoso com cal ou cimento resultam materiais com condições apropriadas de condutividade hidráulica (Ribeiro, 2002) e capacidade de retenção de íons (Rizzo, 2004). Especialmente quando submetidas à percolação de água residuária, tais misturas compactas mostraram tendência de redução da condutividade hidráulica com o tempo, indicando um processo de colmatação (Ribeiro et al., 2004) e redução significativa da carga orgânica representada pela DQO porém, quando tais barreiras são submetidas a condições de campo, outros fatores devem ser analisados, dentre eles o comportamento contráctil. A literatura técnica descreve o comportamento contráctil das misturas solo-cal e solo-cimento como fator limitante de seu uso (Costa, 2005).
A exposição desses materiais ao sol por determinado tempo causa perda d’água, podendo resultar em retrações excessivas e desenvolvimento de fissuras na camada selante; esta fissuração comprometeria o desempenho da camada compactada, favorecendo a percolação de substâncias nocivas à qualidade do solo e da água subterrânea.

O comportamento contráctil de um solo está diretamente relacionado às condições de fluxo de água em seus vazios. Quando há saída de água do solo, as tensões capilares que surgem são responsáveis pela retração. Em oposição às tensões capilares estão as forças coesivas do solo. A existência de algum material cimentante aglutinando suas partículas minerais é outra forma de existência de coesão no solo. Com o uso de aglomerantes como a cal e o cimento a coesão da mistura estabilizada aumenta significativamente podendo resultar em menor retração.

A textura do solo é outro fator significativo no processo, solos de textura mais grosseira, como o estudado, apresentam maiores raio de curvatura do menisco capilar, proporcionando menores alturas de ascensão capilar portanto menores tensões capilares.

No presente trabalho estudou-se o comportamento contráctil das misturas solo-cal e solo-cimento em laboratório, simulando condições consideradas críticas (como longo tempo de exposição ao ar e ao sol); para tanto se realizaram ensaios de caracterização do solo, de compactação do solo puro e de misturas solo-cal e solo-cimento com várias porcentagens de aglomerantes visando-se obter a quantidade ótima de aglomerante a ser adicionado ao solo.

\section{MATERIAL E MÉTODOS}

Os corpos-de-prova destinados a ensaios de retração foram moldados obedecendo aos critérios adotados por Ribeiro (2002) e Rizzo (2004) já que, nessas condições, as misturas apresentaram resultados apropriados de condutividade hidráulica e retenção.

Com relação à energia de compactação, os autores verificaram que a energia proctor normal proporcionava um ganho significativo na massa específica da mistura (com valores de $1,9 \mathrm{~g} \mathrm{~cm}^{-3}$ de massa específica para umidade ótima de $12,5 \%)$, enquanto o ensaio na energia modificada forneceu $2,1 \mathrm{~g} \mathrm{~cm}^{-3}$ de massa específica para $10,5 \%$ de umidade porém os corpos-de-prova mostraram o desenvolvimento de fissuras durante o processo de compactação, comprometendo o desempenho do material em relação à redução da condutividade hidráulica com a compactação.

Concernente ao teor ideal de estabilizante, os trabalhos citados consideraram os teores de 3, 7 e $10 \%$ de cimento e 4,8 e $12 \%$ de cal em massa para definir o menor teor que proporcionasse valores de condutividade hidráulica compatíveis com o uso da mistura como barreira (valores menores que $10^{-10} \mathrm{~m} \mathrm{~s}^{-1}$, Tabela 1 ); outrossim, analisando os valores de condutividade obtidos concluíram que teores de $7 \%$ de cimento e $8 \%$ de cal em massa eram suficientes para se obter condutividades hidráulicas de interesse, adotando assim os parâmetros de compactação exibidos na Tabela 2. 
Tabela 1. Condutividade hidráulica das misturas, Ribeiro (2002)

\begin{tabular}{ccc}
\hline Cura (dias) & Solo-cal $\left(\mathbf{m ~ s}^{-1}\right)$ & Solo-cimento $\left(\mathbf{m ~ s}^{-1}\right)$ \\
30 & $4,25 \times 10^{-9}$ & $3,44 \times 10^{-9}$ \\
60 & $7,28 \times 10^{-10}$ & $1,15 \times 10^{-9}$ \\
120 & $6,47 \times 10^{-10}$ & $8,37 \times 10^{-10}$ \\
180 & $4,21 \times 10^{-10}$ & $3,46 \times 10^{-10}$ \\
240 & $3,67 \times 10^{-10}$ & $3,40 \times 10^{-10}$ \\
\hline
\end{tabular}

A escolha de um solo de textura arenosa e altamente lixiviado foi proposital por se tratar de um tipo de solo bastante comum em grande parte do território brasileiro disponível e, portanto, para uso como barreira; contudo, tal solo não é usado comumente para esta finalidade, pois produz camadas que não atendem às necessidades técnicas de barreiras quando compactadas sem cimento ou cal.

Tabela 2. Parâmetros de compactação das misturas utilizadas

\begin{tabular}{lcc}
\hline Características das misturas & Solo-cal & Solo-cimento \\
Umidade Ótima $\left(\mathrm{W}_{\mathrm{ot}}\right)-\%$ & 14 & 12,5 \\
Massa específica $\left(\rho_{\mathrm{dmax}}\right)-\mathrm{g} \mathrm{cm}^{-3}$ & 1,8 & 1,9 \\
Teor ideal - \% & 8 & 7 \\
\hline
\end{tabular}

\section{Caracterização do solo utilizado}

O solo usado foi extraído de uma jazida de propriedade da Prefeitura Municipal de Ilha Solteira e apresenta, como principais características, a grande espessura de horizonte B exposto em corte (até $9 \mathrm{~m}$ em alguns pontos) e a uniformidade textural do horizonte de solo amostrado. Este solo se desenvolveu sobre substrato da Formação Santo Anastácio (a qual é, na área, composta de arenitos arcoseanos finos a médios, com lentes conglomeráticas) e foi descrito por IPT (1988) e IAC (1994) como Latossolo Vermelho Escuro, eutrófico a moderado, textura média.

Segundo Alcântara \& Lollo (1999) a composição mineralógica principal do solo usado é assim descrita: cerca de $70 \%$ de quartzo (fração areia) e 14\% de hematita; $10 \%$ de gibbsita e 5\% de caulinita, na fração argila.

O solo foi amostrado via cravação de cilindro biselado para obtenção dos índices físicos e na forma de amostras amolgadas para as demais caracterizações, tendo sua massa específica dos sólidos determinada de acordo com a MB-28 (ABNT, 1977a). Além dos ensaios de caracterização do solo foram feitos, também, ensaios de compactação de acordo com a norma MB-33 (ABNT, 1977c) visando obter o teor ótimo de estabilizante.

\section{Moldagem dos corpos-de-prova}

Realizou-se a moldagem dos corpos-de-prova sob um grau de compactação de 95\% como mínimo aceito, pois Ribeiro et al. (2004) concluíram, com tal grau de compactação ser possível garantir a condutividade hidráulica de interesse e as condições de retenção de íons, verificadas por Rizzo (2004).

\section{Condições de exposição dos corpos-de-prova}

Os ensaios de laboratório foram realizados de forma a representar, de forma o mais fiel possível, as condições em que as barreiras selantes são submetidas em campo; para isto, realizaram-se ensaios de retração em corpos-de-prova com di- ferentes tempos de cura, ou seja, 7, 14, 28 e 60 dias, e ensaios em corpos-de-prova imediatamente após sua moldagem, simulando condição de retração logo após a compactação da camada selante.

Os corpos-de-prova ensaiados após períodos de cura foram embalados em sacos plásticos e conservados em câmara úmida de forma a manter sua umidade de moldagem até a data de ensaio, evitando-se que os corpos-de-prova sofressem processo de retração anteriormente à realização do ensaio.

\section{Ensaios para medida de retração}

Para registrar os valores de retração dos corpos-de-prova utilizou-se o ensaio adotado pela metodologia MCT (Nogami \& Villibor, 1995), que é similar ao ensaio de expansão livre, ou seja, usa-se um dispositivo que acomoda os corposde-prova e sustenta o instrumento de medida das variações de suas dimensões.

Os corpos-de-prova foram retirados das embalagens e, em seguida, colocados nas posições em que se desejava fazer as medidas de retração (axial ou diametral); assim, eram realizados o ajuste dos extensômetros e a primeira medida; a partir de então, os corpos-de-prova passavam a perder água para o meio, ocasionando redução de voluma; esta diminuição era acompanhada pelas leituras dos extensômetros, as quais foram realizadas em intervalos de oito horas, até convergência.

Além dessas leituras, foram registradas as temperaturas locais, os horários das leituras e, em algumas delas, a umidade ambiente. A Figura 1 ilustra o esquema usado.

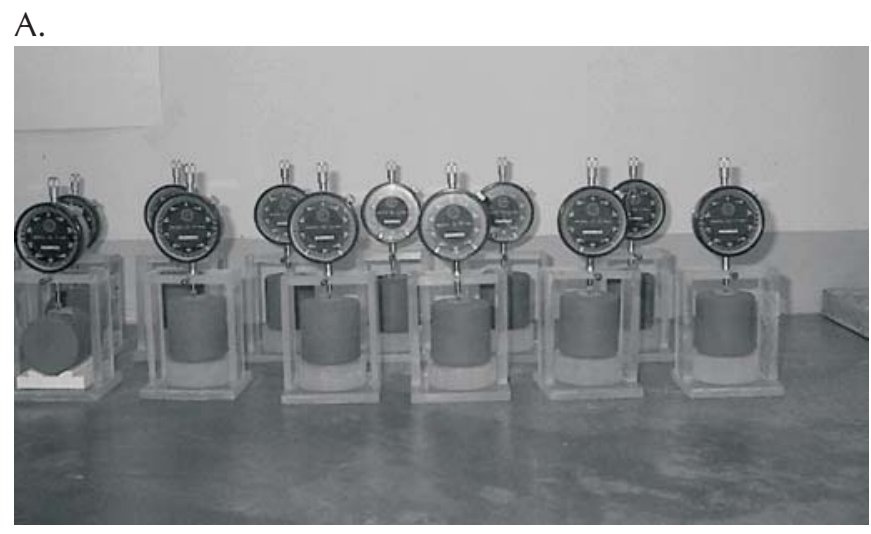

B.

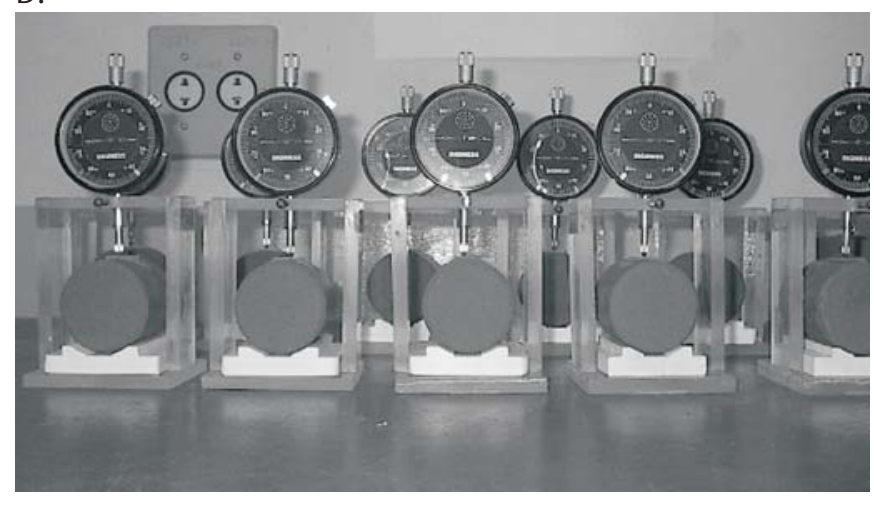

Figura 1. Medição da retração axial (A) e diametral (B) dos corpos-de-prova 
Os valores de retração dos corpos-de-prova foram calculados pela relação do decréscimo da altura (retração axial) ou do diâmetro (retração diametral) em relação à sua medida original, e expressos em percentagem.

\section{RESULTADOS E DISCUSSÃO}

\section{Caracterização do solo}

O solo apresentou massa específica de $1,7 \mathrm{~g} \mathrm{~cm}^{-3}$, umidade natural 13\%, massa específica dos sólidos de $2,7 \mathrm{~g} \mathrm{~cm}^{-3} \mathrm{e}$ índice de vazios de 0,8 . A caracterização textural deste solo, definida a partir de ensaios de granulometria conjunta, segundo MB-32 (ABNT, 1977b), mostrou predominância da fração areia ( $11 \%$ de areia média e $51 \%$ de fração areia fina) e, secundariamente, fração argila (24\%).

\section{Ensaios de retração}

Ensaios com corpos-de-prova foram realizados imediatamente após a moldagem e com o tempo de cura de 7, 14, 28 e 60 dias sendo que, para cada tempo, eram ensaiados dez corpos-de-prova de solo-cal e dez corpos-de-prova de solocimento, dos quais cinco com medidas de retração axial e cinco com medidas de retração diametral. Na Tabela 3 apresentam-se os resultados dos ensaios de retração para os corpos-de-prova de solo-cimento e solo-cal. Os ensaios de retração dos corpos-de-prova de solo sem estabilizante (cinco com medidas de retração axial e cinco com retração diametral) apresentaram os seguintes resultados: retração axial (\%) - 0,55; 0,$61 ; 0,62 ; 0,56$; e 0,56 ; retração diametral (\%) 0,$65 ; 0,65 ; 0,66 ; 0,60$; e 0,62 . Os valores apresentados se referem à retração máxima ocorrida durante o ensaio e são expressos em percentagem.

Tabela 3. Retração axial e diametral para misturas solo-cimento e solo-cal

\begin{tabular}{cc|ccccc|ccccc}
\hline & & \multicolumn{7}{|c|}{ Solo - cal (\%) } & \multicolumn{5}{c}{ Solo - cimento (\%) } \\
$\mathrm{A}$ & 0 & 0,54 & 0,55 & 0,52 & 0,52 & 0,56 & 0,55 & 0,59 & 0,54 & 0,48 & 0,56 \\
$\mathrm{X}$ & 7 & 0,58 & 0,49 & 0,56 & 0,61 & 0,54 & 0,48 & 0,46 & 0,44 & 0,42 & 0,54 \\
$\mathrm{i}$ & 14 & 0,54 & 0,63 & 0,58 & 0,57 & 0,56 & 0,56 & 0,58 & 0,54 & 0,58 & 0,56 \\
$\mathrm{a}$ & 28 & 0,37 & 0,37 & 0,38 & 0,38 & 0,33 & 0,49 & 0,41 & 0,38 & 0,38 & 0,46 \\
$\mathrm{I}$ & 60 & 0,26 & 0,27 & 0,30 & 0,30 & 0,27 & 0,31 & 0,29 & 0,32 & 0,32 & 0,38 \\
\hline $\mathrm{D}$ & 0 & 0,46 & 0,50 & 0,58 & 0,52 & 0,54 & 0,64 & 0,60 & 0,67 & 0,59 & 0,59 \\
$\mathrm{i}$ & 7 & 0,57 & 0,54 & 0,52 & 0,53 & 0,55 & 0,50 & 0,49 & 0,46 & 0,49 & 0,45 \\
$\mathrm{a}$ & 14 & 0,60 & 0,60 & 0,57 & 0,64 & 0,58 & 0,54 & 0,59 & 0,54 & 0,62 & 0,56 \\
$\mathrm{~m}$ & 28 & 0,40 & 0,39 & 0,38 & 0,43 & 0,45 & 0,41 & 0,44 & 0,40 & 0,42 & 0,57 \\
& 60 & 0,30 & 0,33 & 0,32 & 0,32 & 0,26 & 0,32 & 0,32 & 0,34 & 0,35 & 0,32 \\
\hline
\end{tabular}

O tempo de cura mostrou uma influência importante no comportamento contrátil das misturas e uma redução dos valores de retração com o tempo, devido à hidratação das moléculas do aglomerante que faz com que ocorram as reações químicas responsáveis pela cimentação dos grãos do solo. Quanto maior o tempo de cura mais resistente fica a mistura, fazendo com que a perda de água para o meio não conduza a processos significativos de retração.

Ao se analisar os resultados dos ensaios de retração de corpos-de-prova logo após a moldagem e corpos-de-prova com 60 dias de cura, percebe-se esta redução proporcionada pelo estabilizante ao longo do tempo de cura.

Para discutir a eficácia do ensaio de retração livre em amostras compactadas miniatura para simular as condições de retração em barreiras no campo, é oportuno analisar, primeiro, a forma em que tal retração se daria no campo, além de se verificar as diferenças entre as condições de perda d’água nas duas situações.

A perda de água do solo, razão primeira da retração, é função da superfície de solo exposta ao ar e, quanto maior a área de solo exposta ao ar maior será a quantidade de água perdida pelo solo e, assim sendo, é fácil constatar que os corpos-de-prova em laboratório apresentam área exposta significativamente maior já que ficam com toda a área superficial à mostra, ocasionando maior perda de água; deste modo, pode-se esperar que o processo de retração seja menos intenso no campo.

Não foi possível identificar diferenças significativas entre os valores de retração axial e diametral nos ensaios realizados. Os resultados indicam valores percentuais de retração diametral ligeiramente maiores com o tempo porém tais diferenças são muito pequenas (em média 9,64\%).

Não se encontra, na literatura, valor limite de retração para camadas de solo compactadas com a finalidade de barreiras selantes porém Nogami \& Villibor (1995) apresentam uma classificação de comportamento contrátil para corpos-de-prova compactados nas mesmas condições de compactação usadas neste trabalho (massa específica aparente seca máxima da energia normal). Os autores classificam o material como de retração baixa quando a retração máxima é de $0,5 \%$, média quando se situa entre 0,5 e $3 \%$, e elevada quando esse valor é maior que $3 \%$.

No presente trabalho o maior valor foi $0,67 \%$, obtido em um corpo-de-prova ensaiado imediatamente após a moldagem, resultando uma classificação de retração média porém se observa que, quanto maiores os tempos de cura, menores os valores de retração evidenciando a melhora proporcionada pela estabilização química. Os corpos-de-prova ensaiados aos vinte e oito e aos sessenta dias apresentaram contrações abaixo de $0,5 \%$ podendo ser classificados como materiais de baixa retração.

Em termos de tempo de ensaio, nota-se que a maior parte da retração ocorre nas primeiras horas de ensaio diminuindo sua intensidade com o tempo, fato este facilmente verificado em um gráfico de retração vs. tempo, apresentada na Figura 2. Inicialmente, observa-se uma reta ascendente de grande inclinação, nas primeiras horas de ensaio; após esta brusca variação, a curva começa a apresentar um comportamento mais equilibrado com tendência a se estabilizar, apresentando variações volumétricas menos consideráveis.

Ensaios realizados em corpos-de-prova sem a adição de aglomerante não mostraram diferenças significativas entre os valores de retração de corpos-de-prova com e sem aglomerante, sem considerar o tempo de cura; quando se comparam corpos-de-prova sem aglomerante e com aglomerante com tempo de cura superior a vinte e oito dias, percebem-se os efeitos da ação do aglomerante diminuindo a retração, fazendo com que o solo passe a ser classificado como de baixa retração já que, após 28 dias de cura, os corpos-de-prova apresentaram contrações abaixo dos $0,5 \%$. 


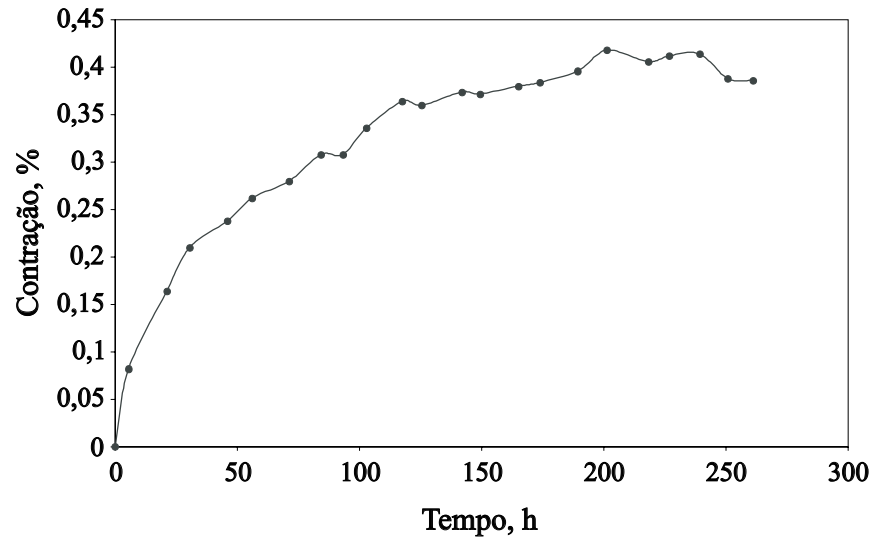

Figura 2. Gráfico de retração x tempo característico para as misturas ensaiadas
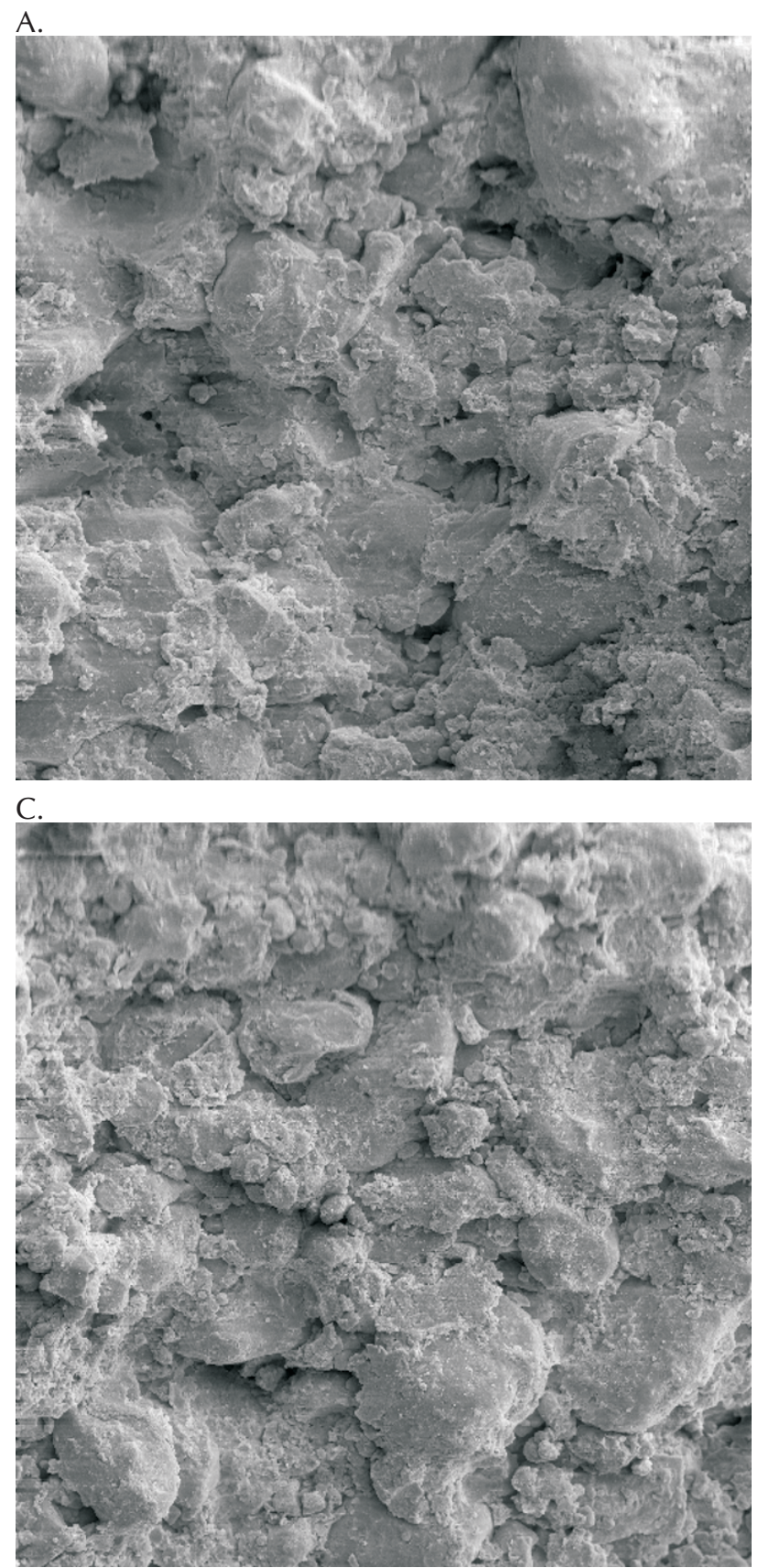

\section{Microscopia eletrônica de varredura - MEV}

Os resultados obtidos mostram forte correspondência com os padrões de retração verificados nos ensaios de laboratório, isto é, todo o processo de retração é pouco significativo e se completa nos primeiros sete dias de ensaio. As características das fissuras de contato entre grãos observados no MEV, em termos de tamanho, abertura e quantidade, não variam com o tempo após o primeiro intervalo (sete dias) independentemente do aglomerante utilizado e cuja situação é ilustrada na Figura 3 que ilustra o solo sem aglomerante (A), e a mistura solo-cimento após sete (B), quatorze (C) e vinte e oito dias (D) de cura ao ar.

As dimensões dos vazios existentes no interior dos corpos-de-prova compactados ilustrados na Figura 3, e sua
B.

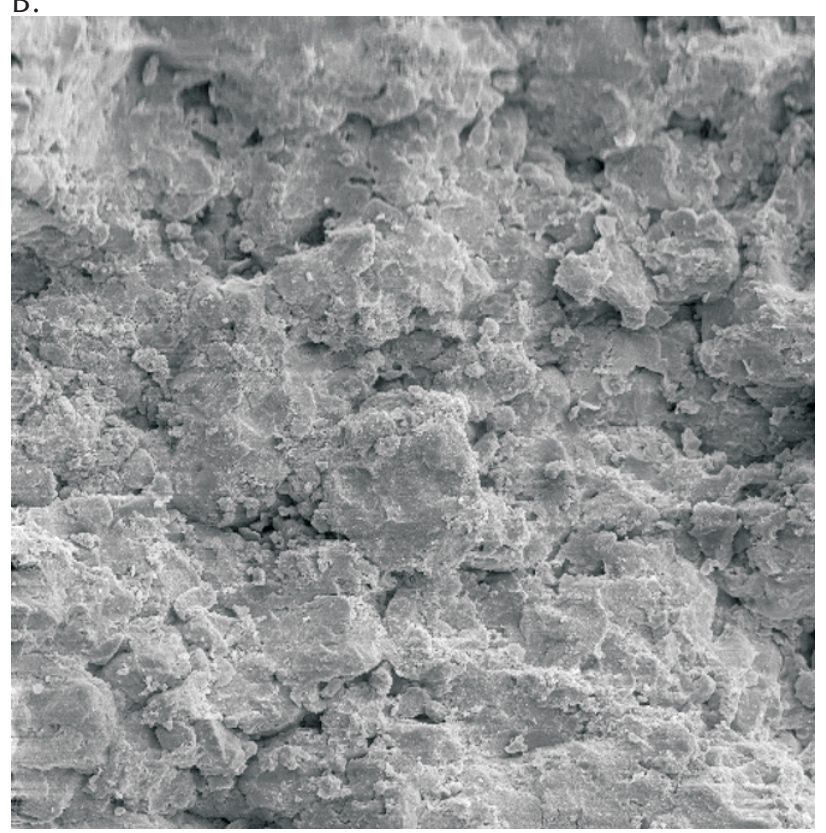

D.

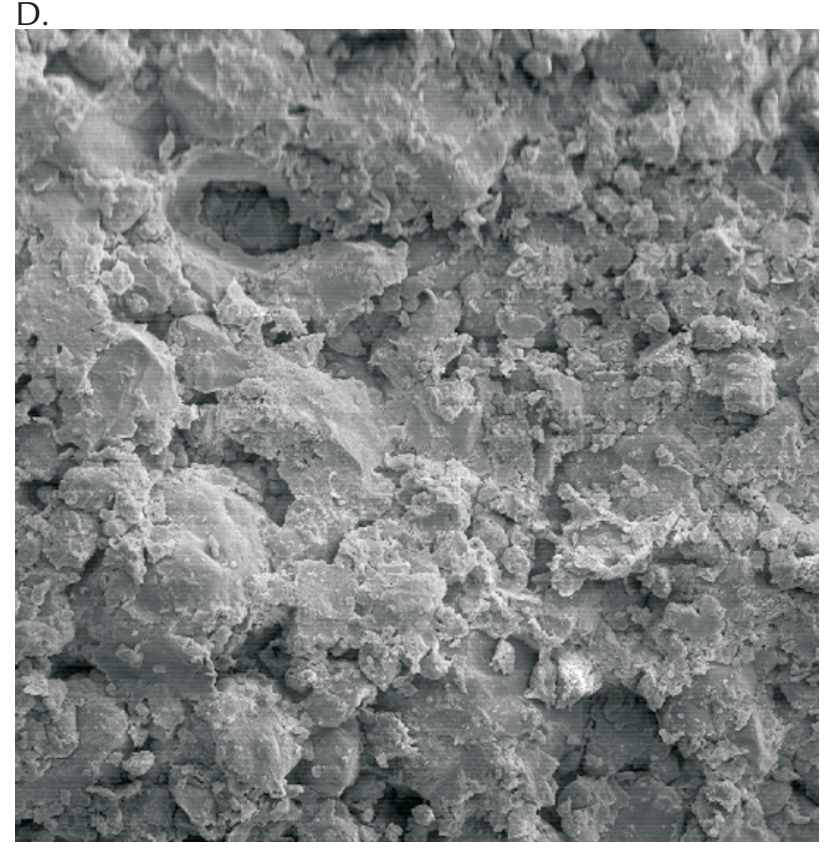

Figura 3. Estrutura do solo compactado: sem aglomerante (A), sete dias de cura (B), quatorze dias de cura (C) e vinte e oito dias de cura (D) 
distribuição uniforme por toda a estrutura observada, indicam que a retração ocorrida nos materiais é pouco significativa. A redução de vazios é mais importante no início do processo de cura (primeiros sete dias) como já havia sido verificado nos ensaios de permeabilidade.

\section{CONCLUSÕES}

1. Os valores de retração obtidos são baixos e justificam o uso das misturas como barreiras de proteção ambiental sendo, portanto úteis para construção de base de lagoas de tratamento.

2. Os corpos-de-prova contendo as misturas indicaram menores valores de retração que o solo puro compactado após vinte e oito dias de cura mostrando que os aglomerantes utilizados (cal e cimento) atuaram reduzindo o comportamento contráctil do solo.

\section{AGRADECIMENTOS}

Os autores agradecem à Fundação de Amparo à Pesquisa do Estado de São Paulo (FAPESP) pelo auxílio à pesquisa (Processo número 02/02455-0).

\section{LITERATURA CITADA}

ABNT - Associação Brasileira de Normas Técnicas: MB-28 Determinação da massa específica dos grãos de solo, Rio de Janeiro: ABNT, 1977a. 12p.

ABNT - Associação Brasileira de Normas Técnicas: MB-32 Análise granulométrica de solos, Rio de Janeiro: ABNT, 1977b. 16p.
ABNT - Associação Brasileira de Normas Técnicas: MB-33 Ensaio de compactação, Rio de Janeiro: ABNT, 1977c. 23p.

Alcântara M. A. M.; Lollo, J. A. Evaluation of mechanic performance of lime-soil mixtures under distinct exposition condition. Journal of Nepal Geological Society, Kathmandu, special issue, v.1, p.162-167. 1999.

Costa. O. P. Avaliação da expansão, retração e resistência à compressão simples de barreiras selantes produzidas com solo laterítico arenoso estabilizado quimicamente. Ilha Solteira: FEIS/ UNESP. 2005, 107p, Dissertação Mestrado

IAC - Instituto Agronômico de Campinas. Levantamento pedológico semidetalhado de alguns municípios da região de influência do Conjunto Hidrelétrico de Urubupungá - Estado de São Paulo. São Paulo: IAC, escala 1:100.000, 1994. 135p.

IPT - Instituto de Pesquisas Tecnológicas. Levantamento pedológico da área do Cinturão Verde da cidade de Ilha Solteira - SP. São Paulo: Instituto de Pesquisa Tecnológicas, escala 1:6.000, 1988. 28p.

Nogami, J. S.; Villibor, D. F. Pavimentação de baixo custo com solos lateríticos. São Paulo: Villibor, 1995, 240p.

Ribeiro, R. A. V. Avaliação do desempenho hidráulico de liners produzidos com solo laterítico arenoso compactado estabilizado quimicamente. Ilha Solteira: FEIS/UNESP. 2002, 87p. Dissertação Mestrado

Ribeiro, R. A. V.; Rizzo, R. P.; Lollo, J. A. Avaliação da condutividade hidráulica de barreiras de proteção produzidas com solo arenoso estabilizado quimicamente. Holos Environment, Rio Claro, v.4, n.2, p.114-129, 2004.

Rizzo. R. P. Avaliação da eficácia de barreiras de proteção ambiental produzidas com solo arenoso estabilizado quimicamente. Ilha Solteira: FEIS/UNESP. 2004, 98p, Dissertação Mestrado 